\title{
Upaya Peningkatan Komunikasi Interprofesional Melalui Interprofessional Collaborative Practice (ICP) (Systematic Review)
}

\author{
Raihany Sholihatul Mukaromah', Luky Dwiantoro², Agus Santoso ${ }^{3}$ \\ ${ }^{1}$ STIKES Bakti Kencana, Bandung \\ 2,3 Fakultas Kedokteran, Universitas Diponegoro, Semarang
}

\section{Informasi Artikel}

\section{Riwayat Artikel:}

Diterima 29 Desember 2017

\section{Kata Kunci:}

Interprofessional

Collaborative Practice (ICP);

Communication

Interprofessional;

Health workers

\begin{abstract}
Abstrak
Peran dan fungsi care provider interdisiplin dalam pelayanan kesehatan masih terfragmentasi sehingga pelayanan kesehatan interdisiplin yang diberikan kepada pasien menjadi tumpang tindih. Fragmentasi interdisiplin dapat diatasi melalui Interprofessional collaborative practice (ICP). Kolaborasi yang baik diantara tim profesional kesehatan sangat diperlukan, agar dapat bertukar informasi dengan jelas dan komprehensif. Kompetensi inti dalam Interprofessional collaborative practice (ICP) adalah komunikasi interprofesional yang efektif. Tujuan dari systematic review ini untuk mengetahui apakah ICP dapat meningkatkan kemampuan tenaga kesehatan dalam melakukan komunikasi interprofesional. Metode yang digunakan Systematic review dengan cara melakukan penelusuran literature data base dari Ebscho, Sciendirect, PubMed dan Google scholar dengan menggunakan advanced search keyword. Kata kunci yang dipilih adalah Interprofessional Collaborative Practice (ICP), Communication Interprofessional, health workers. Pencarian dibatasi pada tahun 2006 2016, pdf full text dan menggunakan bahasa inggris. Kriteria inklusi dari artikel, ini yaitu responden : tenaga kesehatan, intervensi yang digunakan Interprofessional Collaborative Practice (ICP), outcome yang diukur adalah kemampuan komunikasi interprofesional tenaga kesehatan. Didapatkan 6 artikel yang sesuai dengan kriteria inklusi, ke 6 artikel ini dilakukan review. Hasil : masing masing artikel memberikan outcome terhadap peningkatan komunikasi interprofesional dan 2 artikel menghasilkan 3 tema. ICP secara efektif dapat meningkatkan kemampuan tenaga kesehatan dalam melakukan komunikasi interprofesional. Diharapkan pimpinan rumah sakit dapat membuat kebijakan khusus terkait pelaksanaan ICP dan merancang model pelaksanaan ICP yang melibatkan semua profesi kesehatan agar dapat diaplikasikan di pelayanan kesehatan sebagai upaya pengembangan komunikasi interprofesional yang efektif serta meningkatkan kualitas pelayanan kesehatan yang bermutu sehingga peran profesional setiap disiplin berjalan dengan baik.
\end{abstract}

PENDAHULUAN

Saat ini masih terjadi fragmentasi di tatanan pelayanan kesehatan karena tumpang tindihnya peran dan fungsi care provider dengan latar belakang profesi yang berbeda yang dapat mempengaruhi kualitas pelayanan kesehatan. WHO 
menjelaskan bahwa 70 - 80\% kesalahan (error) dalam pelayanan kesehatan disebabkan oleh buruknya komunikasi dan pemahaman didalam tim, kerjasama tim yang baik dapat membantu mengurangi masalah patient safety. Tenaga kesehatan dituntut menjadi interprofesional dalam iklim global sekarang. Menurut WHO (2010), tidak lagi cukup bagi para tenaga kesehatan profesional pemberi asuhan (PPA) untuk menjadi sekedar profesional. Tercapainya pelayanan berfokus pasien, maka asuhan yang diberikan kepada pasien haruslah asuhan yang terintegrasi, dimana semua profesional pemberi asuhan berkolaborasi dalam menjalankan asuhan baik dalam kompetensi praktik maupun edukasi. Sebagian besar rumah sakit di Indonesia belum terlihat kolaborasi tim yang setara. Diperlukan strategi yang dinamis interdisiplin untuk membangun tim pelayanan kesehatan yang profesional yaitu dengan Interprofessional collaborative practice (ICP).

\section{Interprofessional}

practice (ICP) adalah kemitraan antar profesional kesehatan melalui pendekatan kolaboratif dalam pengambilan keputusan terkait proses pelayanan kesehatan (Orchad, Curran, kabene, 2005). ICP sangat diperlukan untuk mempersiapkan para petugas kesehatan menjadi bagian dari peningkatan kualitas kesehatan. ICP merupakan proses kerjasama dan berbagi peran yang berfokus pada masalah klien (Petri, 2010). ICP dapat membentuk equality (persamaan), terkait dengan dimensi peran dan tanggung jawab serta kewenangan dalam memberikan pelayanan yang berfokus pada pasien (patient centered care). Menurut WHO (2010), praktek kolaboratif dapat menurunkan komplikasi pasien total, LOS (length of stay), ketegangan dan konflik antara perawat, pergantian staf, penerimaan rumah sakit, tingkat kesalahan klinis dan angka kematian. ICP dalam lingkungan kerja profesional telah diakui oleh keperawatan, dan tim kesehatan lain serta organisasi profesional kesehatan sebagai komponen penting dalam keselamatan yang mempunyai kualitas tinggi dalam memberikan pelayanan perawatan berpusat pada pasien (Interprofessional Education Colaborative Expert Panel, 2011).

Kolaborasi yang baik diantara tim profesional kesehatan sangat diperlukan, agar dapat bertukar informasi dengan jelas dan komprehensif. Kompetensi inti dalam Interprofessional collaborative practice (ICP) adalah komunikasi interprofesional yang efektif. Komunikasi yang efektif merupakan standar praktek keperawatan profesional terutama dalam memberikan asuhan keperawatan kepada pasien dan sangat penting untuk memecahkan masalah komlpeks. Komunikasi interprofesional efektif dapat terjadi hanya apabila kelompok yang terlibat dalam praktek kolaborasi berkomitmen untuk saling memahami peran profesionalnya dan saling menghargai sebagai individu. Lemahnya komunikasi antar petugas kesehatan dapat mempengaruhi kualitas pelayanan kesehatan yang diberikan, dampaknya dapat menimbulkan kerugian pada pasien dan keluarganya. Systematic review ini bertujuan untuk mengetahui apakah ICP dapat meningkatkan kemampuan tenaga kesehatan dalam melakukan komunikasi interprofesional.

\section{METODE}

Metode yang digunakan yaitu dengan systematic review. Artikel ini dilaksanakan dengan melakukan penelusuran artikel publikasi pada, Ebscho, Sciendirect, PubMed dan Google scholar dengan menggunakan advanced search. Kata kunci yang dipilih adalah Interprofessional Collaborative Practice (ICP), Communication Interprofessional, health workers. Kriteria inklusi dari artikel yang dicari yaitu tipe responden ini memfokuskan pada hasilhasil penelitian yang dilakukan pada tenaga kesehatan, intervensi yang digunakan adalah Interprofessional Collaborative Practice (ICP), outcome yang diukur adalah kemampuan komunikasi interprofesional tenaga kesehatan. Pencarian dibatasi pada tahun 2006 - 2016. Kriteria eksklusi dalam 
systematic review ini adalah artikel yang berupa abstrak saja, aartikel yang tidak menggunakan bahasa inggris, artikel yang di publikasikan di bawah tahun 2006.

Artikel yang telah didapat akan dilakukan pengkajian kualitas studi menggunakan TOOLS CASP (Critical Appraisal Skill Program) yang sudah terstandar dan disesuaikan dengan metode penelitian yang dilakukan dalam artikel tersebut. Tujuan dari pengkajian ini adalah untuk melihat sejauh mana kualitas artikel yang didapatkan. Critical Appraisal pada artikel dilakukan oleh satu orang yang sedang menjalani studi S2 keperawatan semester 3 di Universitas Diponegoro angkatan 2016. Hasil kualitas studi tidak akan mempengaruhi hasil review. Data-data dari hasil temuan yang sudah dianalisis menggunakan Critical Appraisal Tool kemudian diekstraksi dan disintesis untuk mencapai tujuan.

Artikel yang sesuai dengan kriteria inklusi kemudian dilakukan ekstraksi data dengan cara melihat isi artikel. Ekstraksi ini dilakukan dengan menganalisa data berdasarkan beberapa karakteristik yaitu Author, participant, intervention, method dan outcome. Kemudian dilakukan sintesis data dengan mengelompokan data - data hasil ekstraksi yang sejenis sesuai dengan hasil yang ingin diukur untuk menjawab tujuan.

Tabel 1.Strategi Pencarian Literature

\begin{tabular}{ccccc}
\hline Mesin Pencari & $\begin{array}{c}\text { EBSCO } \\
\text { Host }\end{array}$ & $\begin{array}{c}\text { Science } \\
\text { direct }\end{array}$ & $\begin{array}{c}\text { Pub } \\
\text { Med }\end{array}$ & $\begin{array}{c}\text { Google } \\
\text { scholar }\end{array}$ \\
\hline $\begin{array}{c}\text { Hasil } \\
\text { Penelusuran }\end{array}$ & 360 & 200 & 132 & 121 \\
$\begin{array}{c}\text { Fulltext, pdf, } \\
\text { 2006-2016 }\end{array}$ & 53 & 28 & 36 & 18 \\
$\begin{array}{c}\text { Eligible with } \\
\text { inclusy critheria } \\
\text { RESULT }\end{array}$ & 2 & 1 & 3 & 0 \\
\hline
\end{tabular}

\section{HASIL}

Setelah dilakukan pencarian literature ditemukan 6 artikel yang sesuai dengan kriteria inklusi, dimana hasil dari masing masing artikel memberikan outcome terhadap komunikasi interprofesional dan 2 artikel yang menghasilkan 3 tema.

Artikel pertama (Zwarenstein, 2007), menyebutkan sebagian besar tenaga kesehatan mengalami peningkatan komunikasi dalam ICP. Sebagian besar interaksi interprofesional memiliki unsurunsur inti kunci komunikasi kolaboratif seperti pengenalan diri, deskripsi peran profesional, dan permintaan dari sudut pandang profesional lainnya. Budaya komunikasi merupakan dasar kolaborasi yang menjadi bagian rutin dari interaksi interprofesional selama periode kerja terstruktur di bangsal.

Artikel kedua (Diane Morris et al, 2014) menghasilkan 3 tema dalam pelaksanaan ICP yaitu komunikasi, rasa hormat dan kepemimpinan. Hasil ini menunjukkan bahwa banyak profesional tenaga kesehatan yang berpengalaman bekerja dengan baik dalam tim interprofessional mendapatkan manfaat dari ICP dan menjadi aset serta tantangan bagi tenaga kesehatan yang bekerja di rumah sakit terpencil.

Table 2. Hasil Studi

\begin{tabular}{|c|c|c|}
\hline Author & Method & Outcome \\
\hline $\begin{array}{l}\text { Zwarenst } \\
\text { ein } \\
(2007)\end{array}$ & $\begin{array}{l}\text { Multi- } \\
\text { Centre } \\
\text { Mixed- } \\
\text { Methods } \\
\text { Cluster RCT }\end{array}$ & $\begin{array}{l}\text { Kualitatif : dihasilkan } 3 \text { tema } \\
\text { yang memiliki unsur-unsur inti } \\
\text { kunci komunikasi kolaboratif. } \\
\text { Kuantitatif : Sebagian besar } \\
\text { tenaga kesehatan mengalami } \\
\text { peningkatan komunikasi dalam } \\
\text { kolaborasi interprofesional. }\end{array}$ \\
\hline $\begin{array}{l}\text { Diane } \\
\text { Morris et } \\
\text { al (2014) }\end{array}$ & Kualitatif & $\begin{array}{l}\text { Dihasilkan } 3 \text { tema yaitu: } \\
\text { komunikasi, rasa hormat dan } \\
\text { kepemimpinan. }\end{array}$ \\
\hline $\begin{array}{l}\text { Vazirani, } \\
\text { et al } \\
(2015)\end{array}$ & $\begin{array}{l}\text { Cohort } \\
\text { Studies }\end{array}$ & $\begin{array}{lrr}\text { Intervensi } & \text { ICP memberikan } \\
\text { dampak komunikasi dan } & \text { ka } \\
\text { kolaborasi yang lebih baik pada } \\
\text { kelompok } \\
\text { dibandingkan kelompok kontrol. }\end{array}$ \\
\hline Sonya & Cohort & ICP dalam pengaturan \\
\hline $\begin{array}{l}\text { Morgan } \\
\text { et al } \\
(2015)\end{array}$ & Studies & \begin{tabular}{lrr} 
perawatan & \multicolumn{2}{r}{ primer } \\
meningkatkan & kualitas dan \\
kuantitas & komunikasi \\
interprofesional & dan \\
memberikan peluang dalam \\
waktu berkomunikasi.
\end{tabular} \\
\hline $\begin{array}{l}\text { Rashotte } \\
\text { et al } \\
(2016)\end{array}$ & $\begin{array}{c}\text { Quasi } \\
\text { Experiment } \\
\text { al }\end{array}$ & $\begin{array}{l}\text { Dampak dari Electronic Health } \\
\text { Records (EHRs) pada ICP } \\
\text { membantu tenaga kesehatan } \\
\text { mengalami peningkatan di } \\
\text { beberapa model komunikasi. }\end{array}$ \\
\hline $\begin{array}{l}\text { Van } \\
\text { Dongen } \\
\text { et al } \\
(2016)\end{array}$ & $\begin{array}{l}\text { Cohort } \\
\text { Studies }\end{array}$ & $\begin{array}{lrr}\text { Terdapat } 5 & \text { faktor } & \text { yang } \\
\text { mempengaruhi } & \text { kolaborasi } \\
\text { interprofessional } & & \text { dalam } \\
\text { mengembangkan } & & \text { sebuah } \\
\text { rencana perawatan. } & & \end{array}$ \\
\hline
\end{tabular}


Artikel ketiga (Vazirani, et al , 2015) menyebutkan bahwa intervensi ICP memberikan dampak komunikasi dan kolaborasi yang lebih baik pada kelompok intervensi dibandingkan kelompok kontrol. Secara keseluruhan respon dari ICP menurut dokter dan perawat mengalami peningkatan meliputi: proses pengambilan keputusan, bekerja sama dalam pengambilan keputusan, merencanakan bersama-sama dan melakukan komunikasi terbuka.

Artikel keempat (Sonya Morgan et al, 2015) mengatakan bahwa ICP dalam pengaturan perawatan primer dengan menggunakan metode observasi langsung praktek kolaboratif dalam pengaturan pekerjaan sehari-hari memberikan janji sebagai metode untuk lebih memahami dan mengartikulasikan fenomena yang kompleks dalam kolaborasi interprofesional yang dapat meningkatkan kualitas dan kuantitas komunikasi interprofesional dan memberikan peluang dalam waktu berkomunikasi.

Artikel kelima (Rashotte et al, (2016) menyebutkan dampak dari Electronic Health Records (EHRs) pada ICP membantu tenaga kesehatan mengalami peningkatan di beberapa model komunikasi yaitu (a) komunikasi lisan/verbal, elektronik, dan kertas (nonverbal), (b) melalui bagian pasien lintas unit yang berbeda di rumah sakit, (c) seluruh pasien yang tinggal di rumah sakit, dan (d) di beberapa penyedia layanan kesehatan.

Artikel keenam (Van Donge $\mathrm{n}$ et al, 2016) menyebutkan ada 5 faktor yang mempengaruhi ICP dalam mengembangkan sebuah rencana perawatan yaitu kategori: (1) terkait faktor pasien: peran aktif, manajemen diri, tujuan dan keinginan, keanggotaan dalam tim; (2) faktor- yang berhubungan profesional: kompetensi individu, domain cara berpikir, motivasi; (3) faktor interpersonal: perbedaan bahasa/komunikasi, mengenal satu sama lain, kepercayaan dan rasa hormat, dan motivasi; (4) faktor organisasi: struktur, komposisi, waktu, visi bersama, kepemimpinan dan dukungan administratif; dan (5) faktor eksternal: pendidikan, budaya, kekuasaan, cara berpikir domain, hukum dan peraturan, keuangan, informasi dan teknologi komunikasi.

\section{DISKUSI}

Artikel pertama dan kedua masing masing menghasilkan 3 tema, dari kedua artikel tersebut terdapat 1 tema yang sama yaitu peningkatan komunikasi dimana artikel pertama menjelaskan bahwa unsur dari inti kunci komunikasi kolaboratif seperti pengenalan diri, deskripsi peran profesional, dan permintaan dari sudut pandang profesional lainnya. Hal ini didukung oleh Kasperski M. (2000) elemen yang perlu dikuasai oleh para profesional dalam rangka mewujudkan interprofesional kolaborasi adalah komunikasi.

Artikel ketiga dan keempat, menyebutkan secara keseluruhan respon dari ICP menurut dokter dan perawat mengalami peningkatan meliputi: proses pengambilan keputusan, bekerja sama dalam pengambilan keputusan, merencanakan bersama-sama dan melakukan komunikasi terbuka. ICP dapat meningkatkan kualitas dan kuantitas komunikasi interprofesional dan memberikan peluang dalam waktu berkomunikasi. Hal ini sesuai dengan penelitian sebelumnya oleh Galuh (2014) yaitu ada pengaruh yang bermakna antara variabel praktek kolaborasi yang terdiri dari komunikasi, lingkup praktek, kepentingan bersama dan tujuan bersama, secara bersama-sama terhadap kepuasan kerja dokter umum dengan faktor yang paling berpengaruh adalah tujuan bersama. Artikel ke lima berbeda dengan artikel yang lainnya dimana ada penambahan media intervensi pada Interprofessional Collaborative Practice (ICP) yaitu dengan menggunakan Electronic Health Records (EHRs), tetapi mempunyai outcome yang sama yaitu tenaga kesehatan mengalami peningkatan dibeberapa model komunikasi. 
Artikel keenam tidak secara spesifik membahas outcome peningkatan komunikasi interprofesional. Salah satu faktor yang mempengaruhi ICP dalam mengembangkan sebuah rencana perawatan yaitu faktor interpersonal dan faktor eksternal. America Nurse Association menjelaskan kompetensi profesional dalam praktek keperawatan tidak hanya psikomotor dan kemampuan melakukan diagnosa klinik melainkan kemampuan dalam melakukan komunikasi interpersonal. Diperlukan pengetahuan dan keterampilan berkomunikasi di dalam memberikan Pelayanan berpusat pada pasien (patient centered care). Secara keseluruhan outcome dari semua artikel yang dilakukan review yaitu terdapat peningkatan terhadap kemampuan petugas kesehatan dalam melaksanakan komunikasi interprofesional yang efektif. Kekurangan dari systematic review ini proses ekstraksi data hanya dilakukan oleh satu orang, artikel yang digunakan hanya terbatas bahasa inggris dengan intervensi yang diberikan hanya Interprofessional Collaborative Practice (ICP) tidak ada intervensi pembanding.

\section{Kesimpulan dan Saran}

\section{Interprofessional}

Collaborative

Practice (ICP) secara efektif dapat meningkatkan kemampuan tenaga kesehatan dalam melakukan komunikasi interprofesional. Kualitas pelayanan kesehatan dapat dipengaruhi oleh pelaksanaan kolaborasi sehingga diperlukan beberapa upaya dalam meningkatkan Interprofessional Collaborative Practice (ICP) diantaranya pimpinan rumah sakit perlu membuat kebijakan dan merancang model pelaksanaan Interprofessional Collaborative Practice (ICP) yang melibatkan semua profesi kesehatan terkait. Institusi pelayanan kesehatan perlu melakukan sosialisasi dengan memfasilitasi aplikasi Interprofessional Collaborative Practice (ICP) dalam bentuk pelatihan berkala kepada tenaga kesehatan.

\section{DAFTAR PUSTAKA}

Diane Morris et al. 2014. Communication, Respect, and Leadership: Interprofessional Collaboration (ICP) in Hospitals of Rural Ontario. Canadian Journal of Dietetic Practice and Research - Vol 75 No 4

Galuh Pradhi Paramita. 2014. Praktek kolaborasi dokter-perawat terhadap kepuasan kerja dokter umum Di RSUD nganjuk. Tesis Program Studi Manajemen Rumah Sakit Universitas Muhammadiyah : Yogyakarta.

Institute of Medicine : Crossing the Quality Chasm: 2003. A New Health System for the 21st Century,

Interprofessional Education Collaborative Expert Panel. 2011. Core competencies for interprofessional collaborative practice: Report of an expert panel. Washington, D.C.: Interprofessional Education Collaborative

Kasperski M. 2000. Implementation strategies: 'Collaboration in primary care - family doctors and nurse practitioners delivering shared care.' Toronto, ON: Ontario College of Family Physicians

Merrick Zwarenstein. 2007. Structuring communication relationships for interprofessional teamwork (SCRIPT): a cluster randomized controlled trial

Orchard, C.A., Curran,V., Kabene, S., 2005, Creating a Culture for Interdisciplinarry Collaborative Professional Practice. Med.Educ.Online; 10:11 Available at http://www.med-ed-online.org

Petri, L. 2010. Concept Analysis of Interdisciplinary Collaboration. Nursing Forum. 45 (2): 73-83

Rashotte et al. 2016. Mapping communication spaces: The development and use of a toolfor analyzing the impact of EHRs on interprofessional collaborative practice (ICP). International Journal of Medical Informatics 93 (2016) 2-13

Sonya Morgan et al. 2015. Observation of interprofessional collaborative practice (ICP) in primary care teams: An integrative literature revie. International Journal of Nursing Studies. NS-2531

Van Dongen et al. 2016. Interprofessional collaboration regarding patients' care plans in primary care: a focus group study into 
influential factor. van Dongen et al. BMC Family Practice) 17:58

Vazirani, et al. 2015. Effect of a multidisciplinary intervention on Communication and collaboration among Physicians and nurses. American Journal Of Critical Care, Volume 14, No. 1

World Health Organization (WHO). 2009. Human Factors In Patient Safety: Review Of Topics And

World Health Organization (WHO). 2010. Framework for action on Interprofesional Education (IPE) and Collaborative Practice. Diunduh dari http://whqlibdoc.who.int/hq/2010/WHO_HR H_HPN_en 